\title{
Catalytic Pyrolysis of Waste Plastics
}

\author{
Wenger Jorn \\ Av.Venezuela 2007 - Asuncion/Paraguay
}

\begin{abstract}
Plastic pollution is a world environmental problem and with the Catalytic Pyrolysis, there is a sustainable way to recycle the waste and obtain liquid fuel. The process is obtained by using natural catalysts from the clay family of montmorillonites, which can be found in Paraguay. The secret is the exact composition of microelements present in the clay and by adding some elements; a better performance in fuel can be obtained. The process needs temperatures lower than $600{ }^{\circ} \mathrm{C}$ and no pressure in the reactor. A batch reactor was used to make the studies of results in fuel-output and residues (oxides and filler).
\end{abstract}

Key words: Batch reactor, catalytic conversion, fast pyrolysis, pilot plant, plastic waste.

\section{General Views of the Catalytic Process}

The proposal of this project is to use all plastic waste as raw material from the municipal landfills. Plastic pollution is a big world environmental problem because it needs decades to decompose. Used tires can also be used, where you get $25 \%$ to $30 \%$ of fuel, while the rest results in mineral oxides and iron.

I investigated for more than 5 years of the CATALYTIC PYROLYSIS (CP) OF BIOMASS, where I get a performance of $40 \%$ to $45 \%$ of fuels (Sun-fuel). This process can be found in literature as BIOMASS TO LIQUID (BTL). I used bagasse of sugar cane, used kitchen oils and any kind of vegetable oils as biomass. The process of pyrolysis of biomass needs more energy to catalyze.

The performance depends directly on the catalysts. I develop all my catalysts, which are natural clays from the family of montmorillonites. I have my own mine in Paraguay where I make the selection of the active clays to use in the process. Table 1 shows the example of active clay.

\section{Natural Catalysts}

The natural clay can be used directly to catalyze the plastic, with good results, but if you take some

\footnotetext{
Corresponding author: Wenger Jorn. E-mail: dux@pla.net.py.
}

microelements like nickel, cobalt, zinc, and zircon in the formula, you get an increase in fuel output of more than $60 \%$. Also an important fact is the heating of the catalysts in different temperatures. You can increase your output of fuel.

On the following picture the catalyst is shaped like little balls because the catalyst-cartridge was filled for the process. (Fig. 1). Fig. 2 shows the filled catalyst cartridge.

Another important fact is that the catalyst needs to be changed after 8 to 10 process-uses. The remaining catalysts are heated at $1000{ }^{\circ} \mathrm{C}$ and can be reused. The catalyst-activity of the used catalysts is still good.

Using three catalyst-cartridges in the process, filled with different clay formulas, I got a better performance.

\section{Catalytic Process of Plastics}

Working with plastics which raw materials are petrochemicals, you have to degrade the plastics in raw material again. When I catalyze the plastics, I get a family of fuels between $120{ }^{\circ} \mathrm{C}$ to $390{ }^{\circ} \mathrm{C}$.

As a second process, I can make a fractional distillation, and I get separated different fuels, depending on the range of distillation.

But when I condense only one fraction between 120 ${ }^{\circ} \mathrm{C}$ to $390{ }^{\circ} \mathrm{C}$, I get light bunker oil with a density average of $d=0.82$. Bunker oil is used as energy source. 
Table 1 Example of active clay.

\begin{tabular}{lllllllll}
\hline $\mathrm{Al}_{2} \mathrm{O}_{3} \%$ & $\mathrm{Ba} \mathrm{ppm}$ & $\mathrm{CaO} \%$ & $\mathrm{Cr} p \mathrm{ppm}$ & $\mathrm{Fe}_{2} \mathrm{O}_{3} \%$ & $\mathrm{~K}_{2} \mathrm{O} \%$ & $\mathrm{MgO} \%$ & $\mathrm{MnO} \%$ & $\mathrm{Na}_{2} \mathrm{O} \%$ \\
\hline 16.82 & 409 & 0.57 & 52 & 5.87 & 2.53 & 1.21 & 0.05 & 0.99 \\
\hline $\mathrm{Ni} \mathrm{ppm}$ & $\mathrm{P}_{2} \mathrm{O}_{5} \%$ & $\mathrm{SO} \%$ & $\mathrm{SiO} \%$ & $\mathrm{Sr} \mathrm{ppm}$ & $\mathrm{TiO}_{2} \%$ & $\mathrm{~V} \mathrm{ppm}$ & $\mathrm{LOI} \%$ & $\mathrm{SUM} \%$ \\
\hline 26 & 0.01 & 0.09 & 66.73 & 96 & 0.74 & 78 & 4.16 & 99.76 \\
\hline
\end{tabular}

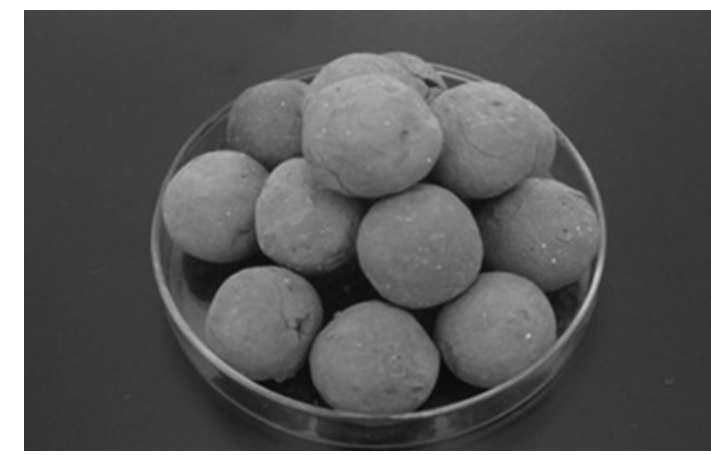

Fig. 1 Catalyst.

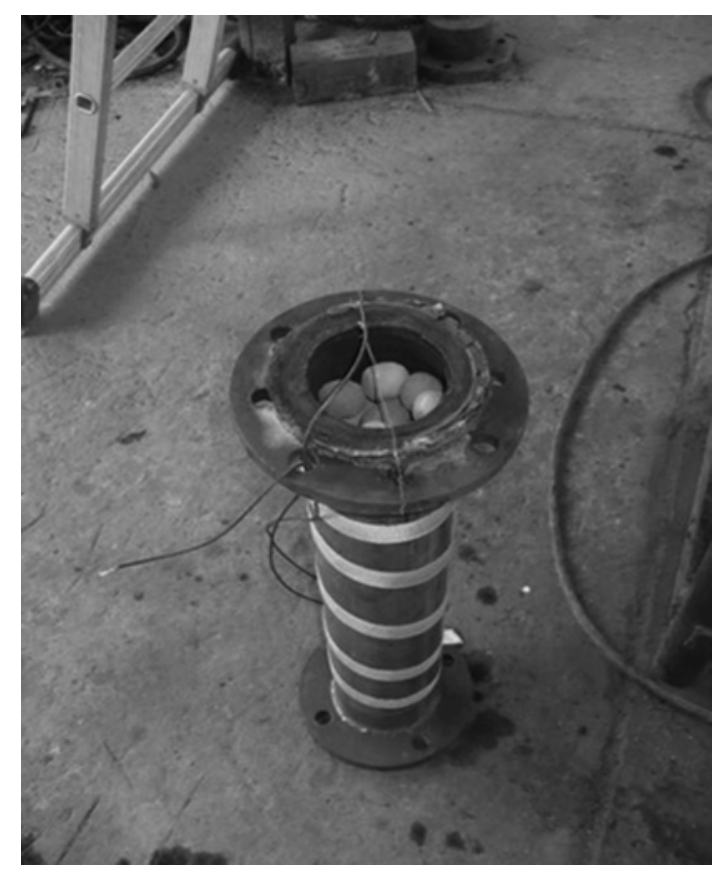

Fig. 2 Filled catalyst-cartridge.

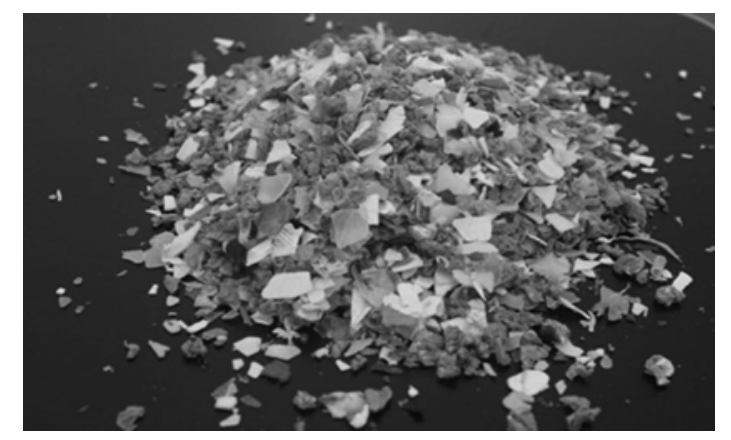

Fig. 3 Plastic waste.
In summary: When I get a performance out of $70 \%$ of fuels, from plastic waste, the project can be auto-sustainable. With oil prices higher than 120 US\$/Barrel, the catalytic pyrolysis of plastic could be an interesting project. Fig. 3 is plastic waste and Fig. 4 is fuel.

My first process of catalytic pyrolysis of waste plastics in the laboratory was satisfactory. Then I made a pilot process in a 60lts CrNi Reactor, with outside electric heating up to $600{ }^{\circ} \mathrm{C}$. After the reactor, come three catalytic-cartridges with different heating temperatures. After the Catalytic-Cartridge, a condenser refrigerated by water was used to get out the different fuels. The whole process is without the presence of oxygen and no pressure.

In Fig. (5), you can see the pilot plant, ready to work. When process begins, heating up the reactor until $200{ }^{\circ} \mathrm{C}$ has been reached, where the plastic is melted and gasified, and has to cross the three heated catalytic cartridges. Then begins the catalytic process. Afterwards, the light gases escape and is extracted outside from the water condenser. After that the fuel begins to condense. Temperature should be always controled in the reactor and cartridges. You have to increase the temperature in the reactor, when the different fractions of fuels condense. The process is

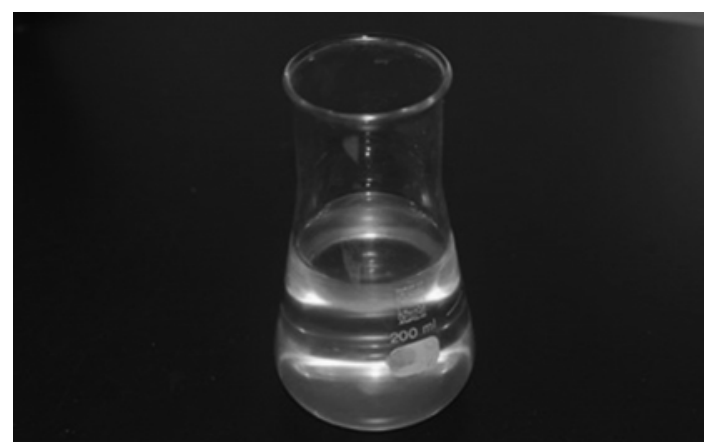

Fig. 4 Fuel. 


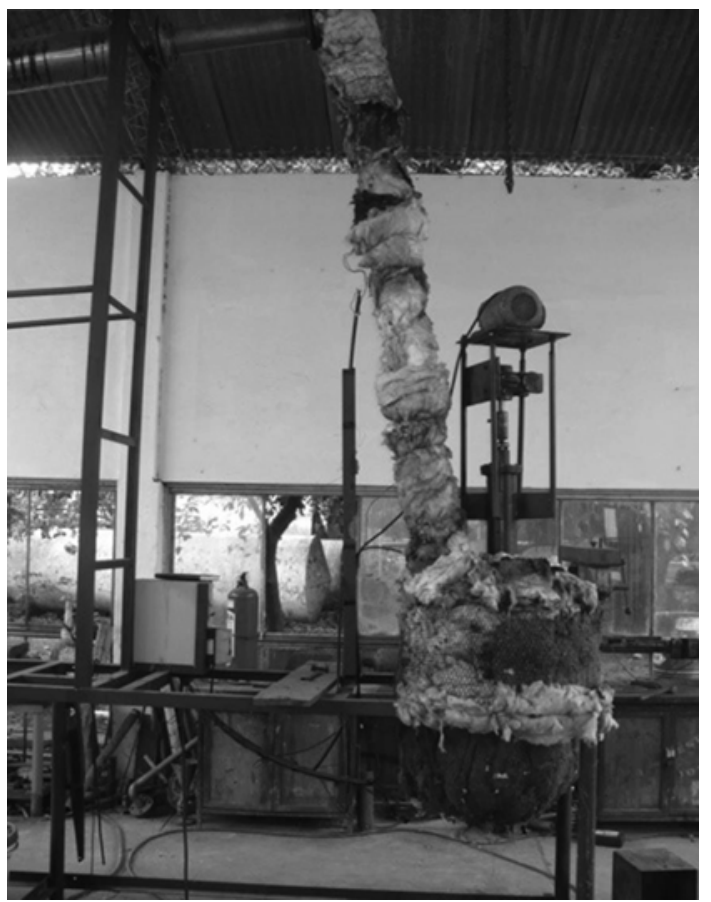

Fig. 5 Pilot plant.

finished when the inside temperature in the reactor is about $400{ }^{\circ} \mathrm{C}$ to $450{ }^{\circ} \mathrm{C}$. But sometimes it is a little bit higher, because it depends on the plastic waste. The other important point is that each catalyst cartridge is heated outside with different temperatures between $120^{\circ} \mathrm{C}$ and $180^{\circ} \mathrm{C}$ controlled by thermostats.

The results were optimal. From $50 \mathrm{~kg}$ of different types of plastic waste, we got 35lts of fuel (Light bunker oil between $120{ }^{\circ} \mathrm{C}$ and $390{ }^{\circ} \mathrm{C}$ ) and $4 \mathrm{~kg}$ as residues (oxides and filler). The rest were light gases, which could not be condensed. Then, if I use a reactor in a bigger version, we have another source of energy to use - the light gases.

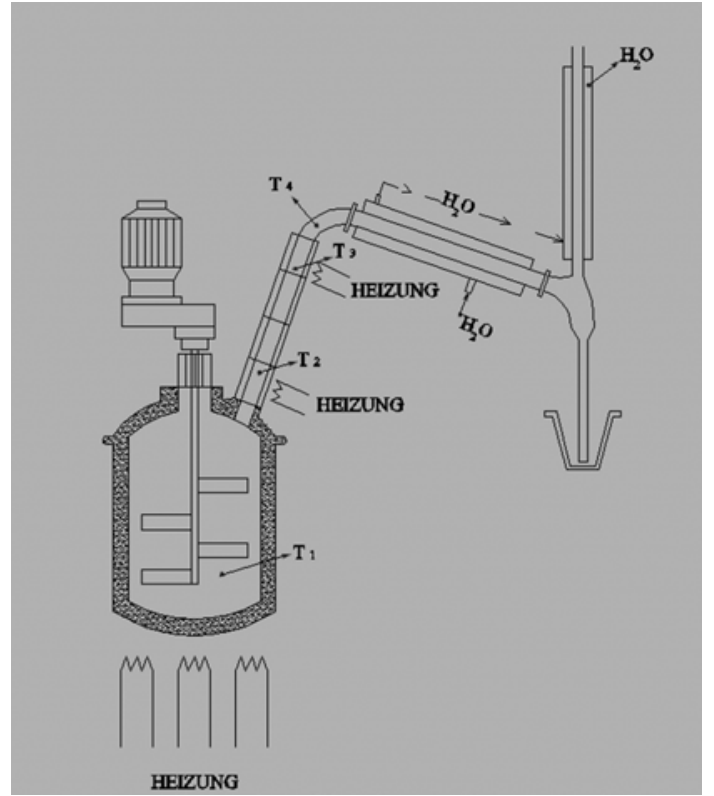

Fig. 6 The batch process.

I was looking forward to make a continuous process, which is more viable than a batch process, due to more plastic waste used per day and a continuous performance of fuel. The batch process looks as Fig. 6.

\section{Conclusions}

\section{References}

[1] Davis, B. H., and Occelli, M. L. 2007. "Fischer Tropsch Synthesis." Catalysts and Catalysis

[2] De la Puente, G., Klocker, C., and Sedran. 2002. "Conversion of Waste Plastics into Fuels." Peer Reviewed Journal, U. Applied Catalysis B 36 (4): 279-285.

[3] Lualdi, M. 2012. "Fischer-Tropsch Syntesis over Cobalt Based Catalyst for BTL Applications.” 